University of New Hampshire

University of New Hampshire Scholars' Repository

\title{
A Competency-based Approach toward Curricular Guidelines for Information Technology Education
}

\author{
Mihaela C. Sabin \\ University of New Hampshire, Manchester, mihaela.sabin@unh.edu \\ Hala Alrumaih \\ Al Imam Mohammad Ibn Saud Islamic University \\ John Impagliazzo \\ Hofstra University
}

Follow this and additional works at: https://scholars.unh.edu/unhmcis_facpub

Comments

This is an Author's Manuscript of an article published by IEEE in 2018 IEEE Global Engineering Education Conference in 2018, available online: https://dx.doi.org/10.1109/EDUCON.2018.8363368

\section{Recommended Citation}

Sabin, Mihaela, Hala Alrumaih, and John Impagliazzo. 2018. "A Competency-Based Approach toward Curricular Guidelines for Information Technology Education." In 2018 IEEE Global Engineering Education Conference. Santa Cruz de Tenerife, Spain: IEEE Xplore.

This Conference Proceeding is brought to you for free and open access by the Applied Engineering and Sciences at University of New Hampshire Scholars' Repository. It has been accepted for inclusion in Applied Engineering and Sciences Scholarship by an authorized administrator of University of New Hampshire Scholars' Repository. For more information, please contact Scholarly.Communication@unh.edu. 


\section{A Competency-based Approach toward Curricular Guidelines for Information Technology Education}

\author{
Mihaela Sabin \\ Applied Engineering and Sciences \\ University of New Hampshire \\ Manchester, NH, United States \\ mihaela.sabin@unh.edu
}

\author{
Hala Alrumaih \\ Al Imam Mohammad Ibn Saud \\ Islamic University \\ Riyadh, Saudi Arabia \\ haalrumaih@imamu.edu.sa
}

\author{
John Impagliazzo \\ Engineering and Applied Science \\ Hofstra University \\ New York, United States \\ john.impagliazzo@hofstra.edu
}

\begin{abstract}
The Association for Computing Machinery and the IEEE Computer Society have launched a new report titled, Curriculum Guidelines for Baccalaureate Degree Programs in Information Technology (IT2017). This paper discusses significant aspects of the IT2017 report and focuses on competency-driven learning rather than delivery of knowledge in information technology (IT) programs. It also highlights an IT curricular framework that meets the growing demands of a changing technological world in the next decade. Specifically, the paper outlines ways by which baccalaureate IT programs might implement the IT curricular framework and prepare students with knowledge, skills, and dispositions to equip graduates with competencies that matter in the workplace. The paper suggests that a focus on competencies allows academic departments to forge collaborations with employers and engage students in professional practice experiences. It also shows how professionals and educators might use the report in reviewing, updating, and creating baccalaureate IT degree programs worldwide.
\end{abstract}

Keywords-information technology education; IT2017; IT competencies; IT curricular guidelines; IT curricular framework

\section{INTRODUCTION}

Computing organizations have spearheaded many efforts to produce curricular documents for computing and engineering studies at the baccalaureate level. One of the more recent documents is a report titled, "Information Technology Curricula 2017: Guidelines for Baccalaureate Degree Programs in Information Technology", known also as the IT2017 report [1], published by ACM in December of 2017. This conference paper provides a summary of the IT2017 report with the purpose of extending the discussion on competencies, which is much misunderstood by computing and engineering people and academicians. Additionally, the intent of this paper is to convey to these communities and to those having an interest in the goals of this conference, the novel approach taken in the IT2017 curricular report and the ways that it shows competencies being crucial to the future of computing and engineering practice. Because of these reasons, this paper represents an extension of the IT2017 report.

Employers across the globe are facing talent shortages. Businesses report significant talent shortage in the information technology (IT) sector [2]. The U.S. Bureau of Labor Statistics has identified the occupations related to computer and information systems as being the largest among occupations in science, technology, engineering, and mathematics [3]. The increasing demand for IT graduates faces the challenge of a long-standing skills gap, the gap between the skills needed to succeed in the professional world and the skills graduates have when they enter the workforce [4]. The most recent national surveys commissioned by the American Association of Colleges and Universities reports similar findings [5]. Students and employers are alike in their perception of how well prepared students are with new technologies. However, in other key areas such as communication, transfer learning to real world situations, or solving complex problems, students overestimate their preparation.

Burning Glass Technologies, a job market research firm, analyzed how skill demands vary across jobs and found that even in highly technical jobs like IT, common and nonspecialized skills that cut across a broad range of job types account for one in four skills demanded by employers [6]. For IT careers, they found that the most valued foundational or baseline skills are communication, organizational, problem solving, research, planning, project management, and customer service.

To meet employers' expectations, baccalaureate IT programs should focus on learning experiences that integrate technical preparation with highly desirable professional skills. This means that IT curricula should shift attention from primarily covering topics to integrative learning environments that develop workplace-relevant IT competencies. The Association for Computing Machinery (ACM), the IEEE Computer Society (IEEE-CS), and other professional organizations have collaborated since the early 2000s to develop and disseminate curricular guidelines for IT baccalaureate programs. Their most recent collaboration has produced the release of a new curricular report titled, Curriculum Guidelines for Baccalaureate Degree Programs in Information Technology (IT2017). The report frames its recommendations toward college and university IT departments and programs around the concept of competency.

This paper presents and discusses a competency-based approach toward developing IT curricular guidelines. It contains an introduction to the main aspects of the report, including guiding principles, review processes, and the report content and organization. The following section focuses on the meaning of competency from a performance perspective of 
learning. It presents an operational definition of IT competencies and it discusses the interplay between its interrelated dimensions of knowledge, skills, and dispositions, particularly in the context of IT professional practice. The IT2017 report applies this definition to the IT curricular framework, intended to enable IT departments to implement, evaluate, and revise baccalaureate IT programs according to their institutional mission and program goals. The paper concludes with presenting the IT curricular framework organization into IT domain clusters, which integrate IT domain scope and content with related competencies.

\section{THE IT2017 REPORT}

Over the years, ACM has spearheaded many efforts to produce a series of curricular documents. In 2008, ACM and the IEEE-CS published the first curricular report for information technology called IT2008 [7]. Since that time, many new technologies emerged and flourished. In 2014, ACM and IEEE-CS collaborated again to form a task group charged with developing guidelines that were appropriately forward looking to prepare graduates in the mid-2020s. The task group produced the IT2017 report, which replaced its predecessor (IT2008) in December 2017.

\section{A. IT2017 Task Group}

The IT2017 task group is the committee that developed these guidelines. Its membership consists of twelve professionals, five of whom form the task group's executive committee. These twelve professionals represent academia (nine) and industry (three). The task group membership encompasses three continents (Asia, Europe, North America) and five countries (Canada, China, Netherlands, Saudi Arabia, United States). The group members represent many international societies, including ACM, IEEE-CS, two ACM special interest groups (IT Education and Computer-Human Interaction), as well as other organizations.

The main goal of the IT2017 task group was to produce guidelines for worldwide baccalaureate IT degree programs that prepare graduates for current and new technologies over the next decade. To accomplish this goal, the task group has incorporated the results of previous curricular reports. These include reports on computer engineering, computer science, information systems, and software engineering. In addition, the group decided to conduct many faculty and industry surveys to ascertain multinational indicators, predictors, and sources surrounding information technology as an academic discipline and industry sector.

Curricular guidelines for high quality, rigorous IT degree programs benefit from a comprehensive approach that engages international perspectives and reflects needs and expectations from industry and IT professional societies [8, 9, 10]. The IT2017 task group has worked diligently to balance feedback from educators, practitioners, and IT professionals to produce a globally relevant report.

\section{B. Vision and Mission}

The IT2017 task group has adopted both a vision and a mission for the project. Its vision is "The IT2017 report will become a sought-after and durable set of guidelines for use by educational institutions around the world to help them develop IT curricula for the next ten years!" Knowledge alone is not sufficient to be productive in the changing information technology world. IT competencies require skills and dispositions that complement knowledge to meet professional expectations of a modern workplace. Therefore, the mission of the IT2017 project is "To produce a globally accepted document of information technology competencies appropriate for baccalaureate degree programs that meets the growing demands of the changing technological world and that is useful for both industry and academia."

\section{Public Comment}

The report includes feedback that the task group received from three public comment and review sessions, solicited for report versions in January 2015, August 2016, and May 2017. Some task group members participated in two international working groups $[10,11]$ to lead extensive data gathering and analysis efforts. The task group garnered input from academia and industry through surveys conducted in 2015 (almost 700 responses, including 91 industry respondents) and in 2016 (over 350 responses from Latin America, including 177 employers). Dissemination of the report development effort included a variety of venues to engage educational and professional communities worldwide: birds-of-a-feather discussion group [12], curriculum design workshop and panel at IEEE EDUCON in Tallinn, Estonia in 2015 [13] and Abu Dhabi in 2016 [14], and a panel at the First National Computing Colleges Conference in Saudi Arabia in 2016 [15]. Other panel sessions on the report status updates occurred in the United States [16, 17], Canada [18], and Peru [19].

\section{IT2017 Report Organization}

The organization of the IT2017 report includes eight chapters and five appendices.

\section{1) IT2017 Report Chapters}

The main body of the report consists of eight chapters. Chapter 1 introduces the report. Chapter 2 discusses the role of IT among other computing disciplines and proposes a new definition for the information technology discipline. It also introduces competencies that students should develop through their program of study that they should demonstrate upon graduation. Chapter 3 highlights the importance of professionalism in the practice of information technology. Chapter 4 discusses the meaning of competencies and proposes an operational definition for information technology competencies. Chapter 5 discusses an industry perspective toward information technology. It includes current data and graphs related to IT competencies from IT employers' viewpoint. Chapter 6 presents an overview of the IT curricular framework. Chapter 7 provides a discussion on the implementation of an IT curriculum. Chapter 8 discusses some challenges that may arise when creating or continuing IT programs such as curriculum design, computing resources, and faculty issues.

\section{2) IT2017 Report Appendices}

The bulk of the material in the report appears as five appendices. Appendix A presents part of the first chapter in the Enterprise Information Technology Body of Knowledge 
(EITBOK) report currently under development by IEEE-CS. Appendix B gives examples of IT performances related to various IT domains and their subdomains. These performances may be useful for developing learning outcomes for a given IT course or possible questions to assess student performance. Appendix $\mathrm{C}$ illustrates typical sample curricula that might appear at different academic institutions together with related mappings of the framework and course descriptions. Appendix D provides samples of other IT programs such as interdisciplinary and three-year programs, or programs that facilitate student transfer from vocational or two-year programs to baccalaureate programs. Appendix E recognizes reviewers and contributors.

\section{E. IT Curricular Framework}

The IT2017 report proposes a learner-centered framework for programs that prepare successful IT graduates for professional careers or further academic study. Inspired by the IT competency model for an associate degree curriculum [20] and receptive to industry demands for a competent and competitive IT workforce, the IT2017 report has adopted a full competency-based approach to learning IT. The framework defines various IT competency domains, indicates the percent of time devoted to an IT curriculum in a degree program, outlines mathematics and science curricular requirements, and further details the competencies that individuals need to become effective professionals in information technology.

The report articulates competencies grounded in content of essential and supplemental IT domains. It enables faculty members to implement IT programs that articulate convincingly what students should be able to achieve by the time of graduation.

\section{INFORMATION TECHNOLOGY COMPETENCIES}

A transmission theory of teaching, also known as teacherfocused, holds that knowledge emerges as it transmits from the expert teacher to the inexpert learners with the objective of 'getting it across' or covering all the topics in the material. The opposing theory of active learning is that students themselves create meaning and develop understandings with the help of appropriately designed learning activities. In undergraduate education, the active learning model underlies a shift of the paradigm that has governed higher education institutions. The traditional paradigm of providing instruction dominated by a passive lecture-based learning environment has shifted to producing learning and creating experiences in which students are active participants in the learning process [21].

\section{A. A Performance Perspective on Learning}

On the continuum of student learning from passive (attending a standard lecture) to active (engaged in problem solving with peers), to increase student engagement means to design learning activities that are more than taking notes, recalling, observing, or describing. Students learn more effectively when their active participation consists of asking questions, applying concepts, discovering relationships, or generalizing a solution to new situations [22]. Higher level of engagement cannot be encouraged if teaching is only about declarative and procedural knowledge: factual information, vocabulary, basic concepts, basic know-how, and discrete skills [23]. Indeed, students need the acquisition of knowledge and development of basic skills, but this is just a means to a more important preparation for authentic performance tasks and for transfer of leaning in new situations.

The highest levels of proficiency learning that students should demonstrate by the end of a course or degree program are performance related. Perkins (1993) and Blythe (1998) formulated a "performance perspective" of learning and offered the view that "understanding something is a matter of being able to carry out a variety of performances concerning the topic" $[24,25]$. A performance perspective of learning transcends the boundaries of a topic, related concepts, and their relationships, and focuses on the development of competencies.

In the rest of this section we examine the meaning of competency, present the working definition adopted by the IT2017 report, discuss how interrelated dimensions of competency (knowledge, skills, and dispositions) affect the development of IT curricular guidelines, and conclude with the IT2017 task group's operational definition of IT competencies.

\section{B. Meaning of Competency}

Learner-centered education focuses on the learner rather than the intentions of the teachers. The literature abounds with clear definitions of learning outcomes [26, 27, 28, 29]. In contrast with the wide agreement on the meaning of learning outcomes, there is extensive confusion and vagueness around the terms of competence and competency. Despite the lack of a precise definition, the terms appear to be useful in bridging the gap between education and professional readiness and preparation [30].

Generally, the term competence refers to the performance standards associated with a profession or membership to a licensing organization. Assessing some level of performance in the workplace is frequently used as a competence measure; that is, measuring aspects of the job at which a person is competent. In short, competencies are what a person brings to a job conceptualized as qualities by which people demonstrate superior job performance [31].

There is general agreement in education that success in college and career readiness requires that students develop a range of qualities [28, 30, 32], typically organized along three dimensions: knowledge, skills, and dispositions. The IT2017 report has adopted a working definition of competency that connects these dimensions, namely:

\section{Competency $=$ Knowledge + Skills + Dispositions}

The triadic model proposed by the Innovation Lab Network's framework for understanding definitional elements of learning that qualify students who exit high school to enroll in college or pursue career opportunities inspires this definition [33]. The model admits that content knowledge is an important factor in student success, but only part of the equation. Educational programs should cultivate increasingly 
complex higher-order skills and mindsets to engage students in meaningful interactions with the world around them that are closely associated with success in college and career.

The working definition of competency in the IT2017 report avoids perpetuating the practice of preponderantly using the knowledge lens and centering curriculum guidelines primarily on a body of knowledge of IT. We note that recent ACM computing curricula reports for IT associates degree programs and graduate programs in information systems have also adopted a competency model approach [20].

\section{Interrelated Dimensions of Competency}

The three interrelated dimensions of competency are mutually reinforcing, have concrete meanings, and can be taught, learned and measured. We are interested in how their interworking affects curriculum development and IT learning assessment and elaborate on each dimension's role as follows.

1) Knowledge: This dimension designates the mastery of core concepts and content of IT and the application of learning to new situations. It usually receives most of the attention from teachers when they design their syllabi, from departments when they develop program curricula, and from accreditation organizations when they articulate accreditation criteria. When asked what an IT course is about or what the requirements of an IT program are, the most pervasive response is the presentation of a list of topics or courses. Selecting, organizing, and communicating curricular content continue to be the easiest tasks in curriculum development.

2) Skills: This dimension refers to capabilities and strategies that develop over time, with deliberate practice and through interactions with others and the world around us [32]. Skills also require engagement in higher-order cognitive activities, meaning that "hands-on" practice of skills join with a "minds-on" engagement. The inextricable connection between knowledge and skills is evident in Michael Polanyi's characterization of explicit versus tacit knowledge [34]. Explicit knowledge, or "know-that", reflects core ideas and principles, and corresponds to the knowledge dimension in IT2017 report definition. Tacit knowledge, or "know-how", is a skillful action requiring sustained engagement and practice. Problem-based assignments, real-world projects, and laboratory activities with workplace relevance are examples of curriculum elements that focus on developing skills. Welldesigned syllabi and accredited programs are mindful of skill development when they articulate student outcomes at course and program level.

3) Dispositions: This dimension encompasses socioemotional skills, behaviors, and attitudes that characterize the inclination to carry out tasks and the sensitivity to know when and how to engage in those tasks [35]. Originating from the field of vocational education and research on career development, dispositions have received increasing attention in the K-12 computer science education community [36]. Formulating an operational definition of computational thinking, Barr and Stephenson [37] included the dispositions category to capture areas of values, motivation, feelings, stereotypes, and attitudes. To distinguish dispositions from knowledge and skills, the IT2017 report uses Schussler's view that a disposition "concerns not what abilities people have, but how people are disposed to use those abilities" [38]. We view dispositions as "know-why" and "know-yourself" when dealing with complexity, ambiguity, bias, difficult problems, tight deadlines, or other conditions surrounding the application of knowledge and skills to the task at hand.

\section{Developing Competency-based Curriculur Guidelines}

The conventional way of framing curriculum guidelines for computing programs has been content driven. A disciplinary body of knowledge, decomposed into areas, units, and topics, tracks recent developments in rapidly changing computing fields. The IT2017 task group acknowledged the limitation of such an approach and it examined the "understanding-by-design" framework [23] to transform the content-based curricular model of the IT2008 report into a competency-based IT curricular framework. A notable application of the understanding by design framework is the Computer Science Principles Framework that informed a set of courses approved by the College Board to prepare students for the new Advanced Placement in Computer Science examination [39]. The idea of the understanding-by-design framework is to treat content mastery as a means, not the end, to long-term achievement gains that a program of study envisions for its graduates. Learners could know and do many discrete things, but still not be able to see the bigger picture, put it all together in context, and apply their learning autonomously in new situations.

Transfer of learning from a classroom environment to the workplace and everyday environments is the ultimate purpose of school-based learning [40]. Understanding-by-design's model of learning has six facets that blend skills and dispositions [41]. Three learning transfer facets pertain to skills that learners attain when they explain, interpret, and apply what they have learned and adjust to situations beyond the classroom. Dispositions related to three additional learning transfer facets complement these skills as follows:

- Show empathy: perceive sensitively; find potential value in what others might find odd or implausible;

- Have self-knowledge: show metacognitive awareness on motivation, confidence, responsibility, and integrity; reflection on the meaning of new learning and experiences;

- Demonstrate perspective: see the big picture, be aware and consider various points of view; recognize and avoid bias.

IT job ads frequently list dispositions as highly desirable by employers such as being enthusiastic, innovative, energetic, self-starter, respectful, or resilient. Inculcating dispositions and inspiring "the ongoing desire to act" responsibly or confidently, for example, comes close to building character [42]. Therefore, teachers and curriculum developers face the challenge of designing learning environments conducive of forming skills and dispositions associated with success in college and careers. 


\section{E. IT Competencies and Professional Practice}

Tyler's hugely influential book Basic Principles of Curriculum and Instruction [43] is a standard reference on ways to develop a dynamic and modern curriculum that supports the production of learning rather than merely providing instruction. Integral to curriculum development are learning outcomes, teaching and learning activities, and assessments of student learning. The basis for constructing a curriculum that is competency-driven is to align learning outcomes, activities, and assessments [44].

On a practical and operational level, people conceptualize competencies as higher-level learning outcomes linked to performance tasks and are descriptive of the professional context of those tasks. We follow Van der Klink and Boon advice that the "fuzziness" of competencies "disappears in the clarity of learning outcomes" [31]. A sensible method to articulate competencies is to select learning outcomes that lead to achieving those competencies along with evaluation indicators suggestive of a professional context [35]. A performance perspective on learning [24] is not possible without performance-based assessments. The design of performance assessments considers authentic situations and aspects of work that professionals encounter and through which they demonstrate expertise. Thus, a promising direction to implement a competency-based curriculum is to identify and link the curriculum to professional contexts.

The operational definition of IT competencies of the IT2017 task group connects knowledge, skills, and dispositions in a professional context (Fig.1). Key characteristics of the IT professional context outline the importance of the following:

- Workplace-bound experiences and relevant IT aspects of work

- Active involvement of employers to support internship and co-op programs and to provide expert mentorship

- Authentic problems and engagement of diverse teams in relevant IT aspects of work

- Collaborative and project-based activities leveraged by using professional tools

- Deliberate and critical reflection on practice to participate effectively in decision-making and to stay engaged in a process of continuous learning.

Answering quiz questions correctly and performing drills skillfully are very simplified means of achievement as they indicate command of facts and basic knowhow. Examples of learning environments that create professional contexts are practicum and internship experiences, projects with real clients, reflective journals of individual contributions to a complex team project, technical presentations judged by external partners, and capstone projects with external evaluators. Instructors can adapt and expand these examples based on institutional priorities, circumstances, resources, and expertise that are specific to individual IT programs.

IT Competencies $=($ Knowledge + Skills + Dispositions $)$ in Professional Context

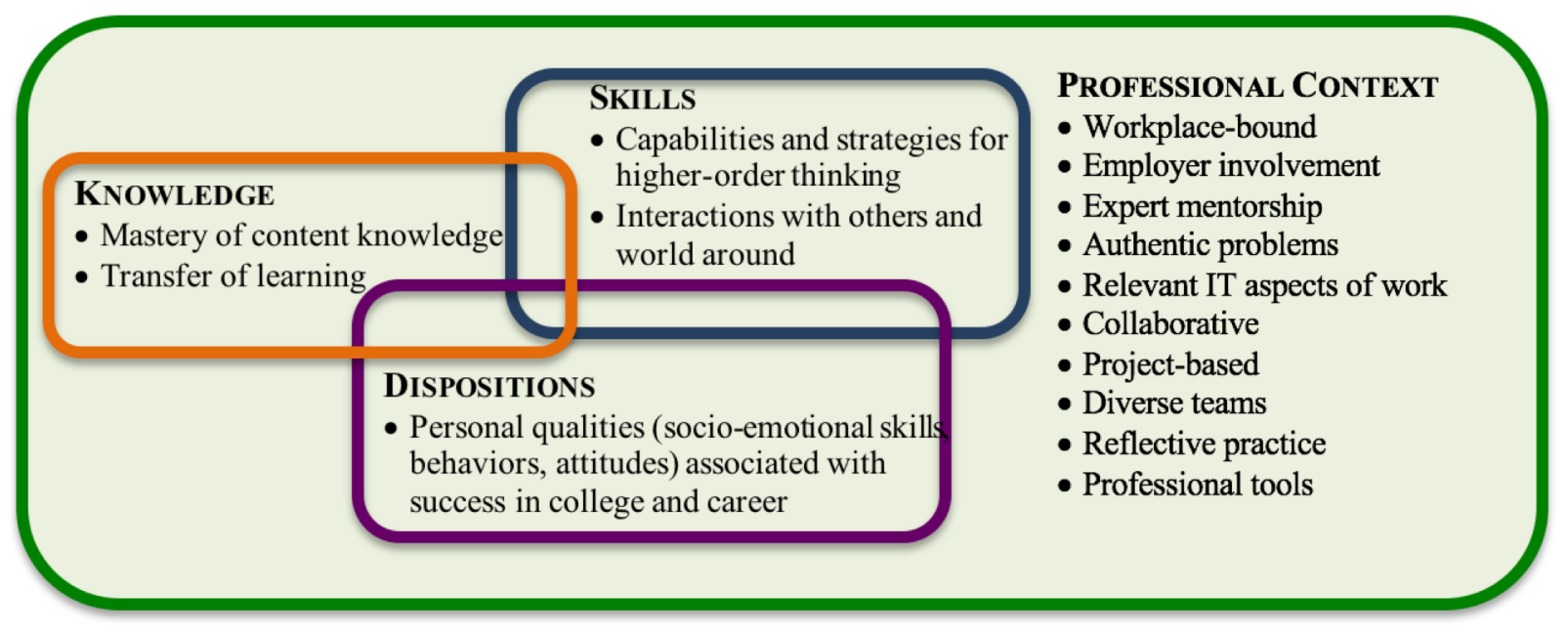

Fig. 1 IT Competency Model 


\section{IMPLEMENTING A COMPETENCY-BASED APPROACH TO INFORMATION TECHNOLOGY EDUCATION}

The IT2017 task group's implementation of a competencybased approach to IT education is the IT curricular framework. This section presents the IT curricular framework in more detail regarding its organization into IT domains and how academic departments can use it to build, evaluate, and revise IT programs of study.

\section{A. Essential and Supplemental Competency Domains}

The IT curricular framework defines the competencies students should possess at the time of graduation and organizes the scope of the IT curriculum for a baccalaureate IT degree program into essential and supplemental competency domains.

- Essential domains encompass competencies that all IT graduates must achieve. They represent minimal competencies that must appear in a complete baccalaureate IT program.

- Supplemental domains encompass competencies in domains where students do more specialized work according to the goals of the program. All IT programs should require students to achieve competencies in some subset of the supplemental domains. Supplemental domains provide IT programs greater flexibility.

Extensive outreach to the educational and professional communities has informed the IT2017 task group on the competency domains that all relevant and forward-looking IT programs should contain. Table 1 lists the competency domains of the IT curricular framework.

TABLE 1. COMPETENCY DOMAINS OF THE IT CURRICULAR FRAMEWORK

\begin{tabular}{|c|c|}
\hline Essential Only (5) & \\
\hline Information Management & \\
\hline $\begin{array}{l}\text { Integrated Systems } \\
\text { Technology }\end{array}$ & \\
\hline Platform Technologies & \\
\hline System Paradigms & \\
\hline User Experience Design & \\
\hline Essential (5) & Supplemental (5) \\
\hline Cybersecurity Principles & Cybersecurity Challenges \\
\hline Global Professional Practice & Social Responsibility \\
\hline Networking & Applied Networks \\
\hline Software Fundamentals & Software Devel. \& Mgmt. \\
\hline Web and Mobile Systems & Mobile Applications \\
\hline & Supplemental Only (4) \\
\hline & Cloud Computing \\
\hline & Data Scalability and Analytics \\
\hline & Internet of Things \\
\hline & Virtual Systems and Services \\
\hline
\end{tabular}

\section{B. Building an IT Curricululm for a Baccalaureate IT Degree Program}

The full curriculum of a complete baccalaureate IT program consists of the IT curricular requirements, together with mathematics, science, and other curricular requirements. The IT2017 report recommends that an institution allocate at least 1.5 years of study to the IT curriculum in a baccalaureate IT program.

For example, in a semester-based baccalaureate IT degree program of 120 credits, one year of study consists of two semesters or 30 credits. Therefore, the IT curriculum represents at least 45 credits or $37.5 \%$ of a total curriculum of a 120-credit degree program. The report further recommends that the mathematics and science curricula be at least $10 \%$ and $5 \%$, respectively, of a baccalaureate IT program.

To map competency domains into the IT curriculum of a baccalaureate IT program, the report considered two principles: (1) give departments flexibility with tailoring their IT programs to the needs of their students, institutional stakeholders, and local industries; (2) keep the domains' scope as small as practical and provide a minimal framework for implementing an IT curriculum in a baccalaureate IT degree program. Guided by these principles, the IT2017 task group recommends that an IT curriculum breakdown into essential and supplemental domains has approximately:

- Map $40 \%$ of the IT curriculum to all essential domains

- Map $20 \%$ of the IT curriculum to some supplemental domains

- Map the remaining $40 \%$ of the IT curriculum to any IT electives.

Using the example of a baccalaureate IT program of 120 credits, Fig. 2 illustrates the breakdown of the IT competency domains, IT electives, math, science, and other curricular requirements.

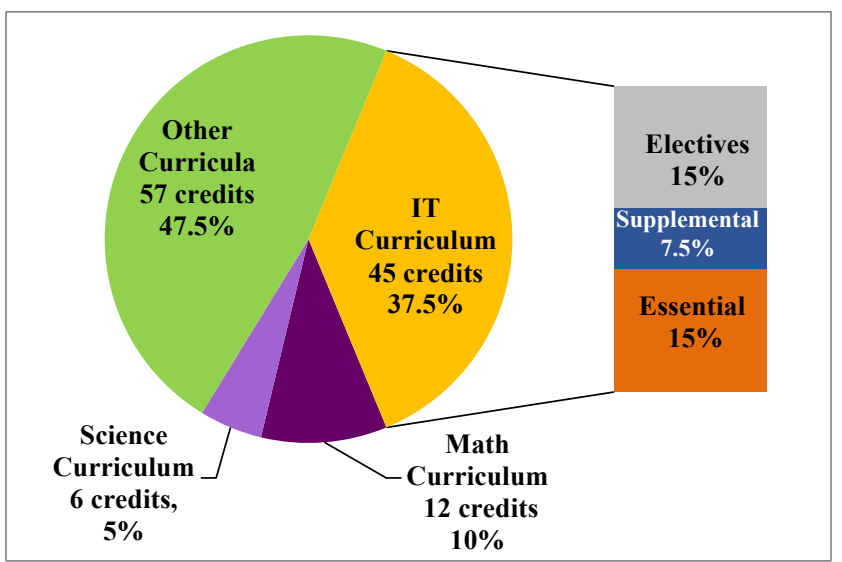

Fig. 2 Example of a curriculum for an IT program of 120 credits 


\section{IT Domain Clusters}

A competency-based IT curricular framework considers the long-term goal of learning to achieve genuine competence through ongoing transfer that spans what students learn through college and graduates develop in their profession. By using a competency-based approach, IT faculty members who implement, evaluate, or update their IT programs need to rethink the IT domains through the lens of performance goals and how students demonstrate what they can do with what they have learned.

To guide departments and faculty members through a competency-based curriculum development process, the report uses IT domain clusters to describe the IT curricular framework's domains. The purpose of an IT domain cluster is to connect directly the scope of the domain with competencies that students achieve within a domain with a more refined characterization of domain content through subdomain information. Table 2 offers an example of IT domain cluster for the Software Development and Management essential domain.

\section{Fostering Competencies in IT Curricula}

A content-oriented teaching and learning environment will focus on the knowledge aspect of a curriculum, at the expense of the other interrelated dimensions of competency, that is, skills and dispositions. Competency is not a new idea and it has existed for decades and even centuries in many areas of professional practice. However, focusing on competencies in computing baccalaureate programs requires rethinking how educators develop and teach a competency-based curriculum. To achieve competency in IT, it is necessary to design learning environments in which students achieve skills and develop dispositions to successfully apply those skills in the context of authentic aspects of IT work.

IT programs can foster skills through increased laboratory experiences, more hands-on involvement, and elevated practice sessions. IT programs can foster dispositions through

\section{TABLE 2 EXAMPLE OF IT DOMAIN CluSTER}

\begin{tabular}{|l|}
\hline \multicolumn{1}{|c|}{$\begin{array}{c}\text { Essential Competency Domain: } \\
\text { Software Development and Management }\end{array}$} \\
\hline Scope \\
\hline $\begin{array}{l}\text { 1. Software process models and software project management } \\
\text { 2. Software development phases: requirements and analysis, design and } \\
\text { construction, testing, deployment, operations, and maintenance }\end{array}$ \\
3. Modern software development and management platforms, tools, and \\
services
\end{tabular}

engagement in problem-based and collaborative learning; increased use of projects in existing courses and preferably with external clients and evaluators; promoting greater participation in industry or government internships and other real-world experiences; and opportunities to reflect and share reflections on professional practice instances.

Competency-based IT programs can foster innovative paths of learning. For example, programs can encourage students to use free electives in areas of study that interest them and represent new domains of applying their IT expertise, such as foreign language study, entrepreneurship and business-related activities, or communication arts and graphic design. A study abroad experience could develop a language skill and cultivate dispositional traits since it involves dealing with foreign people in different settings. An industry experience could perfect a technical skill and develop dispositional abilities by working with diverse people in dayto-day interactions. These suggestions are some ways to increase the level of competency of students graduating from IT programs.

\section{CONCLUSION AND FUtURE WORK}

To become successful IT practitioners and researchers, graduates must demonstrate competencies. By focusing on competencies, academic departments become intentional about forging collaborations with participating employers who share their expertise and have the capacity to engage students in professional practice experiences.

Moreover, it is important to evaluate and modify curricular programs on a regular basis to keep up with the rapid changes in the field. Information technology curricula that already exist today are the product of many years of experimentation and refinement by information technology educators at their own institutions in collaboration with IT professionals and business and industry leaders. Future IT curricula will depend just as much on the creativity and the academia-employer partnerships that follow in the wake of this report to build even stronger information technology programs for undergraduates throughout the world.

\section{ACKNOWLEDGMENT}

The authors thank the ACM for its sponsorship of the IT2017 project activities. They are also grateful to the IEEE Computer Society and to all reviewers and survey respondents whose feedback and support informed the IT2017 report.

\section{REFERENCES}

[1] Task Group on Information Technology Curricula, "Information technology curricula 2017: Curriculum guidelines for baccalaureate degree programs," ACM, New York, NY, USA, 2017.

[2] Manpower Group, "2016-2017 Talent shortage survey,” 2016.

[3] S. Fayer, A. Lacey, and A. Watson, "STEM Occupations: Past, Present, and Future," U.S. Bureau of Labor Statistics, 2017.

[4] PayScale Human Capital, "2016 Workforce-skills preparedness report," 2017.

[5] Hart Research Associates, "Falling short? College learning and career success," Washington, DC: Association of American Colleges and Universities, 2015.

[6] Burning Glass Technologies, "The human factor - The hard time employers have finding soft skills," Burning Glass Careers in Focus, 2015 . 
[7] B. M. Lunt, J. J. Ekstrom, S. Gorka, G. Hislop, R. Kamali, E. Lawson, R. LeBlanc, J. Miller, and H. Reichgelt, "Curriculum guidelines for undergraduate degree programs in information technology. Technical report," ACM, New York, NY, USA, 2008.

[8] M. Sabin, P. Snow, and B. Viola, "Industry and faculty surveys call for increased collaboration to prepare information technology graduates," Journal for computing Sciences in colleges, 31, 6 (June 2016), pp. 7078, 2016.

[9] M. Sabin, J. Impagliazzo, H. Alrumaih, B. Byers, D. Gudoniene, M. Hamilton, V. Kotlyarov, B. Lunt, J.W. McGuffee, S. Peltsverger, C. Tang, B. Viola, and M. Zhang, "Multinational perspectives on information technology from academia and industry," In Proceedings of the 2015 ITiCSE on Working Group Reports (ITiCSE-WGR'15), 2015.

[10] M. Sabin, B. Viola, J. Impagliazzo, R. Angles, M. Curiel, P. Leger, J. Murillo, H. Nina, J.A. Pow-Sang, and I. Trejos, "Latin American perspectives to internationalize undergraduate information technology education," In Proceedings of the 2016 ITiCSE Working Group Reports (ITiCSE'16), 2016.

[11] M. Sabin, H. Alrumaih, J. Impagliazzo, B. Lunt, and M. Zhang, "Designing an information technology curriculum framework to prepare successful graduates in 2025," In Proceedings of the 2015 conference on Innovation \& technology in computer science education (ITiCSE'15). ACM, New York, NY, USA, 2015.

[12] M. Sabin, S. Peltsverger, and C. Tang, "Updating the ACM/IEEE 2008 curriculum in information technology," Abstract Only, In Proceedings of the 46th ACM Technical Symposium of Computer Science Education (SIGCSE'15), 2015.

[13] J. Impagliazzo, "Curriculum design for computer engineering and information technology," In Proceedings of the Global Engineering Education Conference (EDUCON), 2015.

[14] J. Impagliazzo, M. Sabin, H. Alrumaih, and B. Viola, "An information technology competency model and curriculum," In Global Engineering Education Conference (EDUCON), 2016 IEEE, pp. 892-895, 2016.

[15] H. Alrumaih, "ACM/IEEE-CS information technology curriculum 2017: status report," In Proceedings of the 1st National Computing Colleges Conference (NC3 2016). Saudi Arabia, 2016.

[16] M. Sabin, S. Peltsverger, C. Tang, and B. Lunt, "ACM/IEEE-CS information technology curriculum 2017: a status update," In Proceedings of the 17th Annual Conference on Information Technology Education (SIGITE'16), 2016.

[17] M. Sabin, S. Peltsverger, B. Paterson, M. Zhang, and H. Alrumaih, "IT2017 report: putting it to work. in the Proceedings of the 18th Annual Conference on Information Technology Education (SIGITE'17), 2017.

[18] B. Byers, B. Paterson, and C. Hepler, "IT2017 report: panel discussion," In Proceedings of the 21st Western Canadian Conference on Computing Education (WCCE'16), 2016

[19] J. Impagliazzo, E. Cuadros-Vargas, G.B. Escobedo, J.J. Miranda del Solar, M. Sabin, and B. Viola, "Latin American perspectives and the IT2017 curricular guidelines," In Proceedings of the 2016 ACM Conference on Innovation and Technology in Computer Science Education (ITiCSE'16), 2016.

[20] E.K. Hawthorne, R.D. Campbell, C. Tang, C.S. Tucker, and J. Hichols, "Information technology: competency model of core learning outcomes and assessment for associate-degree curriculum. technical report," 2014.

[21] R.B. Barr, and J. Tagg, "From Teaching to Learning: A New Paradigm for Undergraduate Education," Change: The magazine of higher learning, 27(5), pp. 12-25, 1995

[22] J. Biggs, "Teaching for Quality Learning at University - What the Student Does," (1st Edition), SRHE / Open University Press, Buckingham, 1999.
[23] G.P. Wiggins, J. McTighe, and I. Ebrary, "Understanding by design," (Expanded second edition). Alexandria, VA: Association for Supervision and Curriculum Development, 2005.

[24] D. Perkins, E. Jay, and S. Tishman, "Beyond abilities: A dispositional theory of thinking," Merrill-Palmer Quarterly, 39(1), pp. 1-21, 1993.

[25] T. Blythe, "The teaching for understanding guide," San Francisco: Jossey-Bass, 1998.

[26] A. Hargreaves, and S. Moore, "Educational outcomes, modern and postmodern interpretations: response to Smyth and Dow," British Journal of Sociology of Education, 21(1), pp. 27-42, 2000.

[27] L.A. Shepard, "The Role of Assessment in a Learning Culture," Educational Researcher, 29(7), pp. 4-14, 2000

[28] D. Kennedy, Á Hyland, and N. Ryan, "Writing and using learning outcomes: a practical guide," Cork: University College Cork, 2007.

[29] L. Lassnigg, "Lost in translation: learning outcomes and the governance of education," Journal of Education and Work, 25(3), pp. 299-330, 2012.

[30] National Academies of Sciences, Engineering, and Medicine. Supporting Students' College Success; Assessment of Intrapersonal and Interpersonal Competencies. Washington, DC: The National Academies Press. https://doi.org/10.17726/24697, 2016.

[31] M. van der Kink, J. Boon, and K. Schlusmans, "Competences and vocational higher education: Now and in future," European Journal of Vocational Training No 40 - 2007/1, pp. 67-82, 2007.

[32] National Research Council. Education for Life and Work: Developing Transferable Knowledge and Skills in the 21st Century. Washington, DC: The National Academies Press. https://doi.org/10.17226/13398, 2012.

[33] Council of Chief State School Officers. Knowledge, Skills, and Dispositions: The Innovation Lab Network State Framework for College, Career, and Citizenship Readiness, and Implications for State Policy, 2013.

[34] M. Polanyi, "The Tacit Dimension," University of Chicago Press: Chicago, 1966.

[35] D. Kennedy, Á Hyland, and N. Ryan, "Learning Outcomes and Competences. Bologna Handbook. Introducing Bologna Objectives and Tools," Sci Educ Int, 23(3), pp. 1-18, 2009.

[36] C. Stephenson, and J. Malyn-Smith, "Computational thinking from a dispositions perspective,” The Keyword, Google Education., 2016.

[37] V. Barr, and C. Stephenson, "Bringing computational thinking to K-12: What is involved and what is the role of computer science education community?," ACM Inroads, 2(1), pp. 48.54, 2001.

[38] D.L. Schussler, "Defining dispositions: Wading through murky waters," The Teacher Educator, 41(4), 2006

[39] The College Board's Advanced Placement Program. AP Computer Science Principles Course. The College Board, New York, 2017.

[40] J. Bransford, "How people learn: brain, mind, experience, and school," Washington, D.C.: National Academy Press, 2000.

[41] G.P. Wiggins, and J. McTighe, "The Understanding by Design Guide to Creating High-Quality Units," Alexandria, VA: Association for Supervision and Curriculum Development, 2011.

[42] T. Clear, "Thinking Issues: Meeting Employers Expectations of DevOps Roles: Can Dispositions Be Taught?," ACM Inroads, 8(2), pp. 19-21, https://doi.org/10.1154/3078298, 2017.

[43] R. W. Tyler, "Basic Principles of Curriculum and Instruction," University of Chicago Press, Chicago, 1940.

[44] J. Biggs, "Enhancing teaching through constructive alignment," The International Journal of Higher Education Research, 32, pp. 347-364, Springer Netherlands: Kluwer Academic Publishers, 1996. 